\title{
DON QUIJOTE EN LITUANIA
}

\author{
CARMEN CARO \\ Universidad de Vilnius
}

Don Quijote comenzó su andadura por tierras lituanas, y en este arcaico idioma báltico, en la década de los cuarenta. Aunque la novela empezó a traducirse en 1911 y se contaba ya con algunos fragmentos, la traducción completa, ilustrada con dibujos de Gustavo Doré, vio la luz en 1942. El escritor Pulgis Andriušis (1907-1970) se preparó a conciencia para esa imponente tarea, viajó a las tierras por las que el hidalgo caminara con su escudero, y se familiarizó con sus gentes y con su lengua. Tras un ingente trabajo, consiguió llevar a término la traducción de las dos partes del Quijote, con la ayuda del poeta Aleksys Churginas (1912-1990), que revisó la traducción, depurándola y embelleciéndola. Esta misma versión de la obra cervantina se reeditó varias veces en los años de posguerra.

La publicación del Quijote de P. Andriušis se considera un hito de la literatura lituana. La traducción viene introducida por un amplio estudio de Jonas Grinius (19021980), que -con el título de «Cervantes y su Don Quijote»- mereció publicación aparte. En sus estudios sobre el arte y la belleza, el humanista J. Grinius, destacado esteta, crítico y dramatugo, expone su profunda convicción de que toda obra de arte auténtica se eleva por encima del tiempo y, sobre todo, es profundamente humana. «Hay cosas que no envejecen. No es posible imaginar una obra de gran valor, que no tenga algo importante que decir a los hombres». Siempre resaltó la estrecha relación de todo arte con el hombre y con los valores humanos, y no dudaba del poder del arte de unir y fortalecer a una nación. No es de extrañar que este humanista volviera su mirada a Miguel de Cervantes, al que -en la mencionada introducción- sitúa «en la fila de los inmortales, junto a Dante, Shakespeare, Goethe y Dostoievski. Como ellos, fue hijo de su pueblo, pero se elevó por encima de su tiempo, salió de las fronteras de su país y se convirtió en amigo de las personas civilizadas de todos los tiempos.»

Explica ampliamente el contexto histórico, político y cultural en que nació la gran obra cervantina: un momento de profunda crisis, de ocaso político, pero de florecimien- 
to de las artes: literatura, teatro, pintura. Dirigiéndose a un público azotado por la guerra y sediento de libertad, describe la vida de Cervantes, deteniéndose ampliamente en sus aventuras, y muy particularmente en su espíritu de entrega y heroísmo en el periodo de cautividad en Argel. Relata después el regreso a su patria y el depliegue de su actividad literaria. Se detiene a analizar las múltiples interpretaciones del Quijote y la posible intención del autor. Aplicando sus principios estéticos, concede mucha importancia a la crítica que hace Cervantes a través de sus personajes: no censura el autor las novelas caballerescas como género, sino la literatura pobre, de mala calidad y deficiente composición, una literatura que no es verdadero arte, que no ennoblece al hombre, que no tiene nada que decirle. Se refiere también a la crítica de la nobleza española, que vivía de ilusiones y apreciaba más los títulos que la virtud. Se recrea aquí Grinius en los valores humanos que se destacan en la novela, haciendo una alabanza de la noble virtud quijotesca, fundamentada en una filosofía idealista y cristiana. Don Quijote ensalza claramente el valor de la libertad y de la auténtica virtud. Cervantes se burla de los ideales vacíos e infructuosos, sin conexión con la realidad, pero, como tiene amor a su personaje, no crea simplemente a un loco, sino a un idealista. El idealismo es una característica del español, pero también lo es el polo opuesto: el realismo. Cervantes representa con sus dos héroes las dos tendencias de todo hombre, la material y la espiritual. Según Grinius, el Quijote es una de esas obras de verdadero arte, que se ha elevado por encima del tiempo. Su autor, saliendo de la realidad específica hispana, llegó hasta las profundidades de la naturaleza humana. Cervantes y su obra son por tanto grandes e inmortales. La gran novela tiene y siempre tendrá algo que decir al hombre.

Tras la publicación de la traducción de Andriušis, con el completo estudio de Grinius, no se hicieron esperar las reacciones entusiastas de sus contemporáneos. Entre ellos se puede mencionar al escritor y crítico literario Juozas Keliuotis (1902-1983), uno de los hombres de cultura más relevantes del período de entreguerras, con gran influencia en la modernización de la cultura. Relata él mismo en su autobiografía: «Nací a principios del siglo XX, y me ha tocado vivir todas las paradojas de este siglo. Durante mi vida tuvieron lugar dos guerras mundiales, cuyo horror experimenté con todo mi ser; esas guerras no sólo cambiaron la imagen del mundo, sino marcaron mi vida. (...) Yo he experimentado todo el entusiasmo de una Lituania libre y todo el horror de la ocupación del bolchevismo ruso. No me son ajenos ni el espíritu disciplinado y constante de los estudios académicos ni el ambiente algo anárquico de la vida bohemia. (...) Parece que he sido en esencia un hombre del Renacimiento».

En su recensión titulada «El Quijote en Lituania», que se sitúa en el corto periodo que medió entre la publicación de la primera y segunda parte del Quijote, muestra un vivo entusiasmo ante esta traducción, y expresa su enorme agradecimiento tanto al escritor como al revisor del texto. «El nombre de Don Quijote -reflexiona- es conocido en todo el mundo. (...) La obra se ha traducido a todas las lenguas del mundo civilizado, y se pueden hallar Don Quijotes vivos en todas las capas sociales y todas las épocas. Hasta entonces se habían traducido fragmentos y de otros idiomas, por lo que los textos que resultaron poco o nada tenían que ver con la obra maestra. Y ahora aparece toda la traducción hecha a partir del original. Y por eso tenemos tanto que agradecer a Pulgis, que no se valió del método fácil: utilizar traducciones rusas o polacas, sino que aprendió castellano, conoció de cerca la patria del autor del Quijote, y después trabajó un sinfín de 
años en la traducción. Una vez completado el trabajo de traducción, no se precipitó a publicarla, sino que la corrigió y perfeccionó. Acudió a la ayuda del lingüista Churginas, y comprobó con él cada frase, comparó su traducción con la de otras lenguas. Con esta traducción se aseguró un lugar de honor en la literatura lituana, pues una traducción bien hecha a veces sustituye a muchas obras originales. Para una buena traducción de la genial obra hacen falta mucho poder creador, conocimientos literarios y una dedicación larga y constante. Nada de eso le faltó a Pulgis Andriušis. Por ahora bastará a los lectores la primera parte, pues consta de 580 páginas de formato grandes.» No puede dejar de mencionar Keliuotis la completa introducción de J. Grinius, en la que -dice- relata la vida de Cervantes, describe su obra y aporta explicaciones académicas sobre el Quijote mismo. También Grinius ha invertido tiempo y trabajo. No falta el agradecimiento a la Editorial estatal, «que ha conseguido publicar semejante obra en tiempo de guerra. Sin duda, esta publicación les reportará beneficio, pues los primeros diez mil ejemplares salidos al mercado se compraron enseguida. Y los siguientes se comprarán en cuanto se lancen. Nunca se han comprado tantos libros como ahora. En los difíciles años de guerra, el libro es una gran alegría para el hombre.»

Efectivamente el Quijote aparecía en Lituania en un momento en que la nación se encontraba invadida por la Alemania nazi. El pueblo lituano sufría en su propia carne esas paradojas que mencionaba Keliuotis, inevitables en la existencia humana, pero especialmente crudas en esta nación. Invadida por los soviéticos en junio de 1940, y tras las crueles e injustas deportaciones en masa a partir de junio del 1941, había visto en las tropas alemanas a sus liberadores. Enseguida se demostraría que tampoco ellas eran un ejército salvador, sino una fuerza ocupadora y dominadora. Los lituanos vieron frustrados una vez más sus deseos de libertad. En 1944 sufrirán la segunda invasión soviética: de nuevo el terror y las deportaciones.

Se trataba, sin duda, de una nación en busca de sentido, como destacó el insigne humanista y semiótico Algirdas Julius Greimas (1917-1992), que en 1943 publicó precisamente su primer estudio en lituano, titulado «Cervantes y su Don Quijote» (almanaque literario Varpai). Convencido, como J. Keliuotis, de que en la Europa del siglo XX no hay culturas aisladas, sitúa la aparición del Quijote dentro de un amplio marco histórico y cultural, y encuadra la publicación en lituano en una sociedad sedienta de libertad, de optimismo, que busca con ansia el significado de la guerra, de esos horrores. En una Lituania que sabe mucho de luchas, de resistencia, A. J. Greimas da la bienvenida al héroe cervantino: «El noble hidalgo, tan esperado huésped, por fin llegó hasta nosotros. Vino en el momento en que más necesitados estamos de ayuda. En este terrible encuentro de los poderosos del mundo, a este querido país le hace tanta falta esa fe ingenua en su propia misión humana. La aparición del gran optimista en los campos de nuestra literatura realmente puede considerarse el mejor signo, enviado por los dioses. Hay que destacar que la incorporación de Cervantes al tesoro lituano en estos últimos años es quizá el acontecimiento más importante, si no el único, de nuestra vida literaria. Realmente hay que reconocer con vergüenza que no conocemos a los clásicos, ni siquiera intuimos esas posibilidades, que encerradas en las obras de los grandes maestros, se ofrecen a cada caminante de esta tierra como un tesoro común de la humanidad. Son escasas las traducciones de los clásicos y los libros de textos rudimentarios y secos sólo asustan a la juventud y les quitan todo interés por la literatura. (...) Por eso, en este momento en 
que tenemos la suerte de ver una traducción verdaderamente ejemplar de Don Quijote, un placer para la vista y para el alma, mucho más debemos regocijarnos y alegrarnos, agradeciendo a Pulgis Andriušis y a Churginas tanto esfuerzo.

Si cada nación debe aportar su grano al granero de la humanidad, España sólo con la hazaña de Don Quijote ha pagado su deuda, dando un verdadero salto immortale. Como ante cualquier genial obra, también ante la obra de Cervantes, el lector experimenta todo el complejo de la miseria humana, sintiendo no sólo ese abismo que le separa de las alturas de pensamiento de un genio, sino al mismo tiempo entendiendo esa desproporción ingente entre el autor y su época de una parte y de su obra de otra. Incluso la pluma más sofisticada del crítico (...), no acierta a explicar a Don Quijote por Cervantes, el héroe de Lepanto. Seguirá sin explicar esa distancia misteriosa que separa al hombre de la grandeza de la idea creada por él mismo.»

Observa Greimas que tan aventureras fueron las andaduras de Don Quijote bajo el cielo de España, como su azaroso viaje a través del tiempo; los tres siglos de andadura bajo la imaginación de los hombres también le han cambiado y enriquecido, tanto que el mismo Cervantes a duras penas reconocería al querido hijo de su espíritu. Se le ha alabado como el destructor de las locas ilusiones medievales y caballerescas; con lágrimas de risa en los ojos, los niños lo acompañaron en sus hazañas; el Romanticismo puso en su manos la bandera del idealismo; y en el siglo XX el español Unamuno lo convirtió en el luchador por la inmortalidad y profeta de la religión nacional española. Las más variadas interpretaciones de la personalidad del Quijote muestran sólo la grandeza del genio de Cervantes, la riqueza de su obra, y el reflejo de esa simpatía universal, al que responden millones de corazones; «y a nosotros no nos importa mucho qué en realidad quiso decir el autor y qué dijo. Lo que está vivo es lo que yo y tú, lector, encontramos en el libro, y pienso que nosotros sobre todo queremos hacer amistad con el bondadoso hidalgo y su sabio escudero.»

Y con ese trato de amistad, «Don Quijote nos enseñará cómo conseguir la inmortalidad, aún a costa de parecer ridículos. Pues todo el que no vive de acuerdo a su tiempo parece divertido: el que quiere recobrar el pasado soñado, y el que ansía acercarse a la edad de oro de la humanidad que se divisa en el lejano horizonte. Él nos enseñará cómo luchar con los molinos, sin temer el ridículo.»

Además de perder el miedo al ridículo, a parecer grotescos, entre las lecciones que A. J. Greimas señala está la de no querer buscar una vida fácil. «Participando en sus charlas amistosas y sinceras, oyes muchas enseñanzas. (...) Aprendes de Sancho cómo, sin hacer caso de la risa de la multitud, hay que luchar por el derecho y el deber del hombre de crear su propio destino, ser «artífice de su ventura». Qué gran cosa es proteger y defender la espontaneidad del propio carácter. (...) Ves que el noble caballero no busca la felicidad, y que Dulcinea no le prepara, como Isolda a Tristán, un blando lecho de musgo y hojas. No le importa la felicidad: busca la realización completa de su vida, su significado (...). Entiendes que por encima de ese mundo de imágenes pobres y desvaídas, hay otra realidad más verdadera, más hermosa: el mundo de pensamientos y formas creado por el propio hombre según su imagen divina. Y Don Quijote te dice: piensa en cosas grandes, pues la idea es la única realidad del mundo. Eleva la naturaleza hasta tu nivel, y que todo el mundo sea sólo un reflejo de tu alma heroica. Lucha por el honor, sólo eso es de verdad digno del hombre; y si te hieren, derrama tu sangre, como rocío reparador, y 
sonríe». En un país devastado, puede ser Don Quijote el inspirador de una lucha por la libertad, que es tarea ardua, pero llena de sentido, y -sugiere Greimas- es posible luchar con optimismo, soñando con cosas grandes. No es casual que Jonas Mackus, uno de los partisanos de la resistencia anti-soviética que murió en la lucha el 14 de diciembre de 1952, escogiera precisamente el seudónimo «Don Kichotas».

Como se ha dicho, la traducción de P. Andriušis se reeditó en varias ocasiones en las décadas siguientes. La ansiada libertad, que se veía muy lejana por los años cuarenta, llegó por fin en 1990. Justamente durante los últimos años de esa década el experimentado traductor Valdas Petrauskas (1938- ) preparaba una nueva traducción del Quijote, que lanzó al mercado en 1995, en una edición anotada con una primera tirada de 10.000 ejemplares. Se había preparado concienzudamente durante varios años, pero no consiguió de las autoridades soviéticas el permiso para viajar a España; no se le consideraba persona suficientemente «fiable», como a tantos humanistas.

Se incluye en la edición de V. Petrauskas un artículo del propio traductor titulado «Personaje y personalidad en la novela de Cervantes Don Quijote». Hace una introducción histórica y encuadra la novela en el contexto de la literatura renacentista. Se refiere ampliamente al autor, a su obra literaria, y por fin al Quijote, comentando ampliamente la evolución de su interpretación a lo largo de la historia, e incluyendo aspectos de otros géneros literarios que se aprecian en la novela (del teatro y del relato corto); hace una mención de la aparición del falso Quijote, y su influencia en el Quijote de Cervantes.

Sitúa también V. Petrauskas la gran novela entre los clásicos e inmortales. El personaje loco se ha convertido en héroe, inspirador de grandes hazañas. La esencia, sin embargo, no está en las hazañas, sino en su espíritu, en la forma de ver el mundo, de enfrentarse con la realidad. Desea que la nueva traducción del Quijote brinde al lector de nuestros días una oportunidad de sumergirse en el mundo de este gran escritor español, y contemplar nuestra actualidad con otra mirada.

Aunque no deja de sorprender el silencio crítico tras la fantástica traducción de V. Petrauskas, no perdió esa fuerza el héroe después de la ansiada libertad. El 1 de mayo de 2003 se inauguró oficialmente en la ciudad de Panevėzys, al norte de Lituania, el único monumento a Don Quijote de los países bálticos. La escultura de bronce, cobre y acero, de 2,6 m. de altura, está situada en el patio del teatro «Menas», que, fundado en 1991, tiene como filosofía la «lucha quijotesca». En la escultura, obra de Henrikas Orakauskas, Don Quijote sostiene una lanza alrededor de la cual vuelan mariposas de cristal de variopintos colores. El alcalde de la ciudad, en la ceremonia de inauguración, sugirió al público reunido la idea de iniciar una nueva tradición: los que han planeado hacer buenas obras y desean éxito, pueden tocar la escultura del símbolo del humanismo para que les dé suerte.

Llegó el Quijote a Lituania después de un largo caminar por esos tres largos siglos, pero llegó con toda su fuerza, con toda su carga romántica e idealista, con todos los valores humanos que -destacan los grandes humanistas lituanos- son universales y alcanzan a todos los corazones. Llegó el esperado huésped a una tierra llena de paradojas, a una Lituania ansiosa de libertad y de buena literatura, que lo recibió como al luchador idealista, al héroe inmortal, pero sobre todo como a un buen amigo. 


\section{BIBLIOGRAFÍA}

Miguel de Cervantes Saavedra, Išmoningasis idalgas Don Kichotas iš La Mančos (traducción de P. Andriušis y A. Churginas, con ilustraciones de G. Doré), Valstybinė leidykla, Kaunas 1942.

SERVANTESAS, Išmoningasis idalgas Don Kichotas iš La Mančos, Valstybinès grožinès literatūros leidykla, Vilnius 1959.

Migelis DE SERVANTESAS Saavedra, Išmoningasis bajoras Don Kichotas lamančietis (traducción de Valdas Petrauskas), Vaga, Pasaulinès literatūros biblioteka, Vilnius 1995.

AlgiRDAS J. Greimas, «Cervantes ir jo Don Kichotas», en Varpai, Literatūros almanachas, Šiauliai 1943, 221-227.

GRINIUS, J. Servantesas ir jo Don Kichotas, Kaunas 1942 (Atspaudas iš Servanteso Išmoningojo idalgo Don Kichoto iš La Mančos I dalies vertimo, išleisto Valstybinès Leidyklos, Kaune 1942 metais).

—, Grožis ir menas, Mintis, Vilnius 2002.

Keliuotis, J. «Don Kichotas Lietuvoje» (autógrafo, archivo de J. Kelioutis), recensión sobre la traducción de Don Quijote de P. Andriušis (Kaunas 1942).

—, Mano autobiografija, Lietuvos rašytojų sajungos leidykla, Vilnius 2003.

JuRGa Perminaitė-Katkuvienè, Servanteso Don Kichotas, Baltos Lankos, Vilnius 2000.
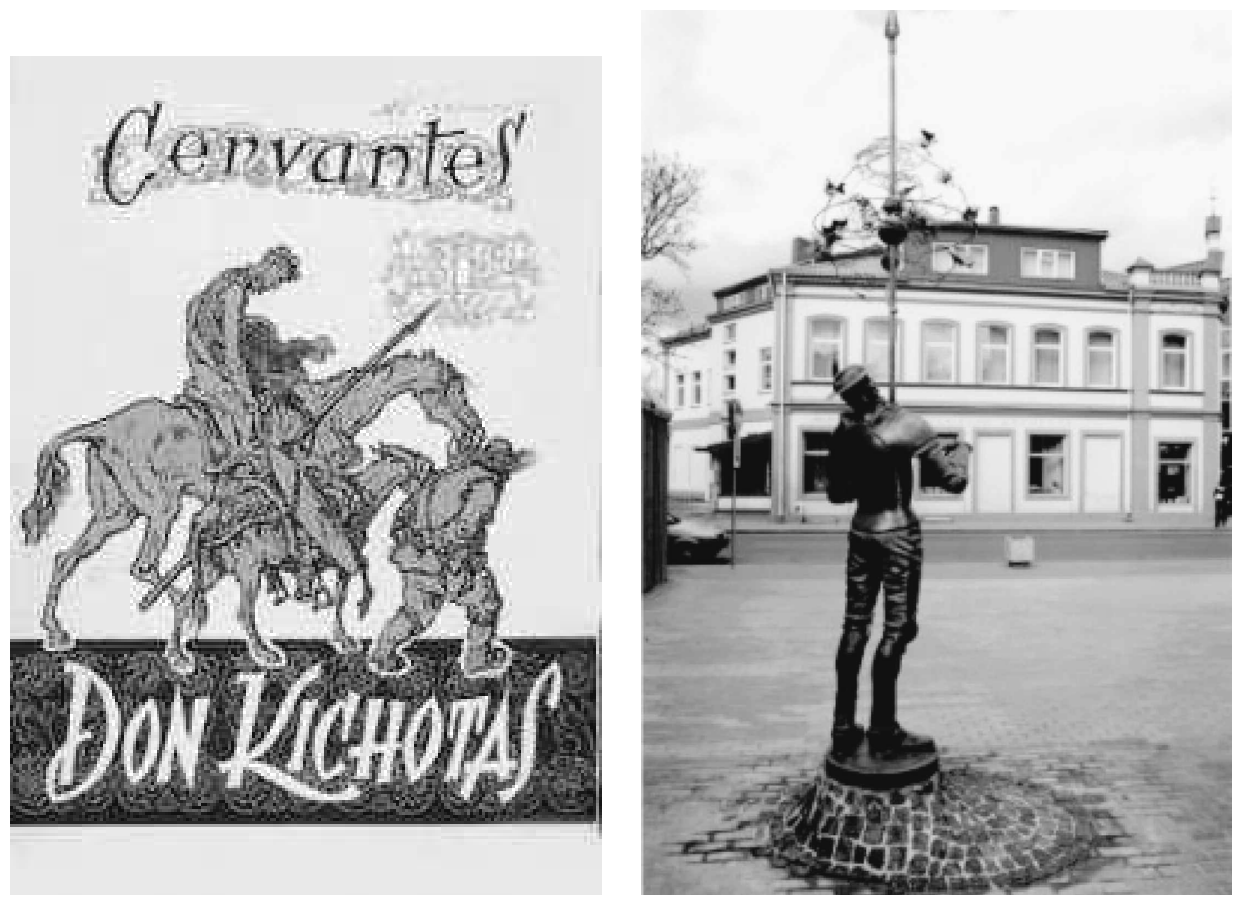